\title{
A identidade de um perfume: análise da relação entre design de embalagem $\mathrm{e}$ mensagem publicitária
}

Camila Assis Peres Silva (USP, Brasil)

camila.assis@usp.br

Avenida Prof. Almeida Prado, 1280, Butantã

São Paulo, SP. CEP: 05508-070

Clice Sanjar Mazzilli (USP, Brasil)

clice@usp.br 


\title{
A identidade de um perfume: análise da relação entre design de embalagem e mensagem publicitária
}

Resumo: Este artigo faz parte de uma pesquisa de doutorado na área de design de embalagens para perfumes, cujo objetivo é investigar as possibilidades de tradução dos cheiros em elementos visuais. Em paralelo ao papel do design na comunicação dos efeitos que um perfume propõe desencadear, temos a mensagem publicitária com seu forte apelo verbal. Argumentamos que, para um resultado eficaz, o design deve estar em consonância com tal apelo verbal. Um dos vieses dessa pesquisa de doutorado é investigar a relação que embalagem e mensagem publicitária podem estabelecer. Nesse artigo apresentamos um estudo inicial que explora a percepção do consumidor quanto a relação entre linguagem visual e verbal. Para tanto, selecionamos um caso real de mercado, no qual o consumidor não tem contato com o produto, isto é, um catálogo virtual de perfumes. Realizamos uma pesquisa virtual com consumidores para identificar se as mensagens publicitárias estavam em consonância com a embalagem dos perfumes. Os resultados são aqui apresentados e discutidos.

Palavras-chave: Perfume, Design, Publicidade, Brasil

\section{Perfume's identity: analysis of the relationship between packaging design and advertising message.}

\begin{abstract}
This paper is part of a doctoral research in the field of packaging design for perfumes, whose aim is to investigate the possibilities of translating smells into visual elements. In parallel to the role of design in communicating the effects that a perfume proposes to elicit, we have the advertising message with its strong verbal appeal. We argue that for effective result the design must be in line with such verbal appeal. One of the biases of this doctoral research is to investigate the relationship packaging and advertising message can establish. In this paper we present an initial study that explores the consumer's perception of the relationship between visual and verbal language. We selected a real case of market in which the consumer has no contact with the product, i.e., a virtual catalog of perfumes. We conducted a virtual consumer survey so as to identify whether the advertising was consistent with the packaging of perfumes. The results are presented and discussed here.
\end{abstract}

Key words: Perfume, Design, Advertising, Brazil 


\section{As linguagens verbal e visual na identidade de um perfume}

Esse estudo investiga uma das facetas do mercado de perfumaria, a comunicação dos atributos de uma fragrância. O mercado de perfumaria envolve uma cadeia de profissionais das mais diversas áreas, que atuam desde os processos de concepção do perfume até sua distribuição para o mercado consumidor. O que nos interessa analisar, porém, é o papel do design nessa cadeia. Em especial, no que concerne ao design daquilo que o mercado brasileiro considera como embalagem primária, isto é, frasco e tampa. Embora aspectos técnicos como proteção e transporte de perfumes sejam primordiais no design de uma embalagem, aspectos de linguagem visual exercem bastante influência no final da cadeia de produção, no momento de decisão da compra. Além disso, o perfume é um produto onde questões de ordem emocional são tão ou mais relevantes que questões de ordem técnica. "Dele não dependemos para o asseio básico e diário, porém grande parte dos produtos de higiene e cuidados pessoais é perfumada" (sIlva, 2012, p.25). Perfumar-se é de fato um hábito nacional. O crescimento do mercado de perfumaria nas últimas décadas é um reflexo disso ${ }^{1}$.

Outrora uma exclusividade das camadas mais altas da sociedade, hoje o perfume está disponível para os diferentes grupos sociais. Tal como a moda, tem adquirido a função de assinalar identidades sejam elas constantes ou efêmeras (SIlVA, CAMPOS, Lima, 2011). Ao analisar as mensagens publicitárias utilizadas para descrever as fragrâncias, podemos observar o apelo emocional na comunicação. De fato, os perfumes tem uma forte conexão com a emoção e a memória. Capazes de atingir um dos mais primitivo dos sentidos, o olfato, as fragrâncias são recebidas e processadas pelo chamado sistema límbico. Responsável por regular os impulsos primitivos e coordenar as funções sensoriais e sexuais, o sistema límbico está diretamente relacionado ao desejo sexual e o comportamento emocional (MALNic, 2008, p.18). Diante de tal fato, torna-se imprescindível um estudo da linguagem a ser utilizada de forma a traduzir para o consumidor os atributos de uma fragrância.

Identificar visualmente um cheiro é uma tarefa não muito fácil. Além do cheiro evocar percepções que variam de indivíduo a indivíduo, cientistas afirmam que os humanos possuem dificuldades de construir imagens dos cheiros e de verbalizá-los (WOLfE et al., 2012). Eles afirmam ainda que podemos detectar e discriminar centenas de odores, mas reconhecê-los não é tão

1. Panorama do setor. In: ABIHPEC. Associação Brasileira da Indústria de Higiene Pessoal, Perfumaria e Cosméticos Disponível em <http://www.abihpec.org.br/wp-content/uploads/2014/01/Panoramado-setor-PORT-10jan2014.pdf> Acesso em 12/06/2014. 
fácil. Apesar disso, o mercado da perfumaria tem investido na construção de um vocabulário de forma a facilitar a identificação e discriminação de odores (TeIXeira et al., 2013; ZARzo \& STANTON, 2009; DONNA, 2009). Na prática de mercado, um perfume é comercializado sob o suporte da publicidade e do design. Dois são os principais meios de comunicação dos atributos de um perfume: o discurso publicitário e o design da embalagem. Ambos estão interligados na comunicação de um perfume. No entanto, enquanto a publicidade se vale principalmente da linguagem verbal o design de uma embalagem se caracteriza especialmente pela linguagem visual. O desafio que se impõe para uma comunicação síncrona e eficaz é compreender como representar um discurso verbal através do visual. Não apenas isso, mas como a linguagem verbal e visual juntas podem representar um cheiro, isto é, como influenciar a percepção olfativa através da linguagens de outra natureza.

Na concepção de um perfume é comum a caracterização deste através de adjetivos e associações a elementos do nosso cotidiano. Logo, a linguagem verbal quase sempre precede a visual, ou seja, precede o design de uma embalagem. Apesar disso, as características visuais de um perfume também são relevantes, como têm demonstrado alguns estudos realizados no campo da psicologia. As diferentes cores e as formas de uma embalagem podem estabelecer de uma relação mais ou menos síncrona com determinadas fragrâncias (Кiм, 2013; DeMATtÈ et al., 2006; мORRot et al. 2001; GILBERT et al., 1996). Portanto, faz-se necessário que o design de uma embalagem esteja em consonância não apenas com a fragrância mas também com a mensagem que a publicidade anuncia.

\section{Pesquisa com consumidores: perfume, embalagens e percepção}

Com base na hipótese de que as linguagens visual e verbal devem estar em consonância para potencializar a comunicação dos atributos de um perfume, realizamos uma pesquisa com um grupo de consumidores. O objetivo foi identificar a percepção destes com relação a discurso publicitário e design de embalagens. E por consequência, avaliar se as mensagens utilizadas por uma determinada empresa de perfumes, para endossar suas fragrâncias, estavam de acordo com suas embalagens. Elegemos os perfumes da Avon para esta pesquisa pelo fato da empresa possuir um site exclusivamente ${ }^{2}$ para

2. O site Perfumaria Avon apresenta toda a linha de perfumes comercializada em território nacional pela empresa Avon. Disponível em <http://www.perfumariaavon.com.br/perfumes>. Acesso em $20 / 08 / 2014$ 
comunicar os atributos dos seus perfumes. Além de ser uma das maiores empresas atuantes em mercado nacional de perfumaria ${ }^{3}$.

\subsection{Materiais e métodos}

Dada a natureza exploratória da pesquisa, optamos pela elaboração de questionário para ser disponibilizado na internet. Utilizou-se a ferramenta de formulários da empresa Google ${ }^{\odot}$ para elaboração do questionário. Um link de acesso ao questionário foi distribuído através da rede social dos autores, composta majoritariamente por designers e estudantes de design. No entanto, a ocupação profissional não foi um quesito de definição da amostragem. Os participantes foram estimulados a divulgar a pesquisa em suas respectivas redes sociais. Não foi definido um público alvo específico por considerarmos que os perfumes em análise são produtos de consumo de diferentes grupos sociais. Os dados demográficos coletados restringiram-se a idade, gênero e cidade de residência. No período de 03/11/2013 a 17/12/2013, obtivemos um total de 171 participantes, dos quais 110 eram mulheres e 61 homens. A maioria possui até 35 anos ( $72 \%$ ), seguido por 13\% com idade de 36 a 45 anos, $7 \%$ de 46 a 55 anos e $7 \%$ acima de 56 anos. A amostra compreende majoritariamente em residentes da Região Sudeste do Brasil (90\%), dentre os quais a maior parte moradores do estado do Rio de Janeiro (74\%), seguido por moradores de São Paulo (12\%), Minas Gerais (3\%) e Espírito Santo (1\%).

O questionário foi estruturado em três partes: (1) Dados pessoais; (2) Momento da compra; (3) Perfumes e suas mensagens. Em "Momento da compra" o objetivo era ratificar a importância da embalagem não apenas como proteção mas como artefato de decisão de compra. Duas situações foram apresentadas: compra de perfume para uso pessoal e compra de perfume para dar de presente. A primeira pergunta foi "O que você considera importante em um perfume para você usar?". Enquanto que a segunda foi "Se você vai dar um perfume de presente, o que você considera importante?". Para cada uma das perguntas o participante tinha as seguintes opções de resposta: (a) Um perfume bom mesmo que a embalagem não seja muito atraente; (b) Uma embalagem atraente mesmo que o perfume não seja muito bom; (c) Tanto o perfume quanto a embalagem devem ser atraentes.

Na seção 'Perfumes e suas mensagens' as perguntas tinham por objetivo investigar se as mensagens atribuídas pela empresa a cada uma das fragrâncias estavam coerentes com as embalagens, na opinião dos participantes. As embalagens dos perfumes selecionados foram editadas no programa de computador Photoshop $^{\oplus}$, de forma a eliminar a marca do perfume e qualquer

3. De acordo com o site da revista Exame, a Avon está em terceiro lugar no ranking do mercado brasileiro de perfumaria, com 8,3\% de participação em 2013. Disponível em <http://exame.abril.com.br/ negocios/noticias/ boticario-desbanca-natura-e-vira-lider-em-perfumes>. Acesso em 20/08/2014. 
outro texto que houvesse na embalagem. Para elaboração das perguntas foram selecionados dez perfumes da empresa Avon, sendo cinco perfumes femininos (Instinct, Pure Blanca, BlueRush Paradise, Far Away Exotic, Eternal Magic Enchanted) conforme figura 1 e cinco masculinos (True Force, Ironman Extreme, Spirit, Signature, Christian Lacroix Nuit) conforme figura 2.
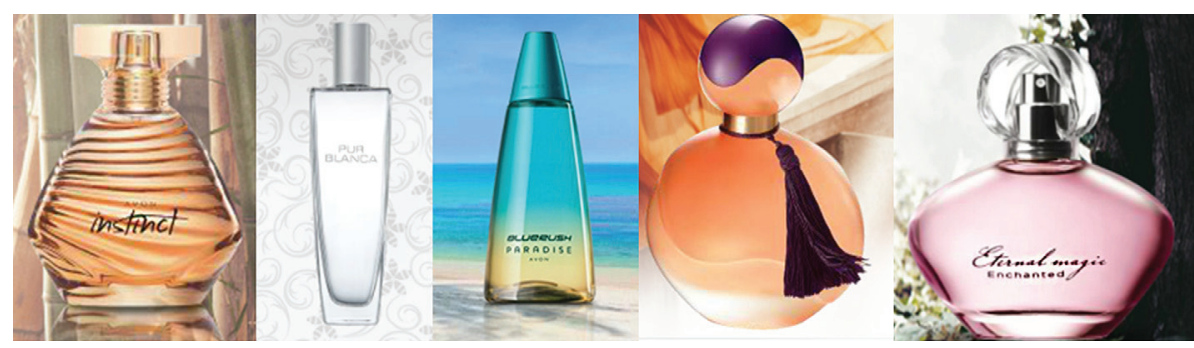

Figura 1. Perfumes femininos selecionados para pesquisa.

Fonte: http://www.perfumariaavon.com.br/perfumes/fragrancias.php (2014).
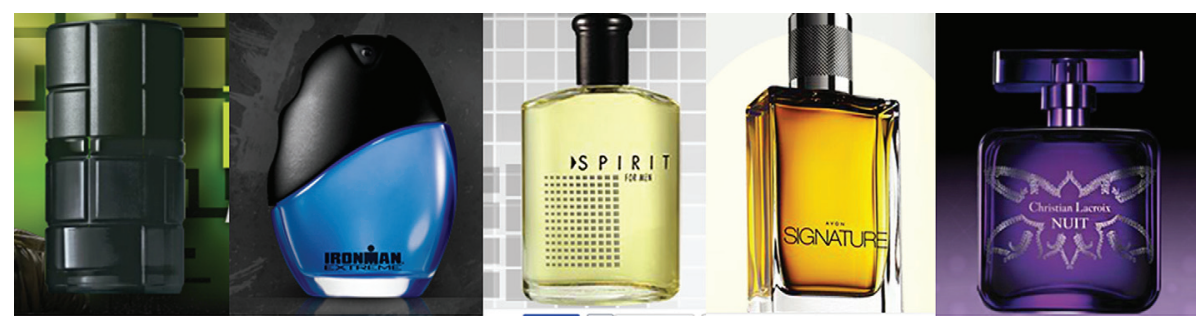

Figura 2. Perfumes masculinos selecionados para pesquisa

Fonte: http://www.perfumariaavon.com.br/perfumes/fragrancias.php (2014).

Cada um dos perfumes selecionados é apresentado no site da empresa através de um discurso que enaltece as características da fragrância (ver tabelas 1 e 2). A partir dos dez discursos extraídos da publicidade dos perfumes em questão, foram selecionados seis, três para perfumes femininos e três para masculinos. A seção 'Perfumes e suas mensagens' iniciava-se com a seguinte sentença 'Observe as embalagens abaixo e indique qual delas melhor representa as seguintes frases'. Em seguida uma imagem com os perfumes femininos editados era apresentada com uma legenda numerando as embalagens de 1 a 5 (figura 3). Abaixo das imagens eram apresentados os textos dos perfumes femininos Pure Blanc, Instinc e Far Away Exotic nessa mesma ordem. Após os perfumes femininos, uma imagem das cinco embalagens editadas de perfume masculinos foi apresentada. As embalagens dos masculinos foram identificadas por letras de A a E (figura 4), para evitar confusão com os perfumes femininos. Para os perfumes masculinos foram selecionados os textos de Ironman Extreme, Spirit e Christian Lacroix Nuit. 


\begin{tabular}{l|c|l}
\hline $\begin{array}{l}\text { Nome dos } \\
\text { perfumes }\end{array}$ & $\begin{array}{l}\text { Código usado } \\
\text { na pesquisa }\end{array}$ & Descrição da fragrância \\
\hline Instinct & 1 & $\begin{array}{l}\text { Liberte seus desejos mais selvagens com esta fragrância } \\
\text { que combina a refrescância de folhas verdes, exóticas } \\
\text { camélias e a sensualidade do sândalo. }\end{array}$ \\
\hline $\begin{array}{l}\text { Pure Blanca } \\
\text { BlueRush }\end{array}$ & 2 & $\begin{array}{l}\text { Fragrância delicada, com direção olfativa floral } \\
\text { amadeirada, indicada para o dia. Mantém-se serena no } \\
\text { caos, pois nada nem ninguém interfere em seu equilíbrio. }\end{array}$ \\
\hline $\begin{array}{l}\text { Paradise } \\
\text { Exotic Away }\end{array}$ & 3 & $\begin{array}{l}\text { Mergulhe no contraste inusitado das notas frescas de } \\
\text { tangerina com a feminilidade das suaves pétalas de } \\
\text { gardênia, envolvidas pela sensualidade da baunilha. }\end{array}$ \\
\hline $\begin{array}{l}\text { Eternal Magic } \\
\text { Enchanted }\end{array}$ & 4 & $\begin{array}{l}\text { Uma viagem inspiradora interpretada por um mix } \\
\text { de especiarias do Oriente e rosa de açafrão, com a } \\
\text { sensualidade do musk e âmbar. }\end{array}$ \\
\hline & 5 & $\begin{array}{l}\text { A feminilidade é Eterna e o Encantamento faz parte da } \\
\text { alma feminina. Uma fragrância sofisticada para enaltecer } \\
\text { todo poder de encantamento da mulher moderna e } \\
\text { contemporânea. }\end{array}$ \\
\hline
\end{tabular}

Tabela 1. Discurso verbal de cada um dos perfumes femininos selecionados.

Fonte: Elaborado pelos autores com base na pesquisa (2014).

\begin{tabular}{l|c|l}
\hline $\begin{array}{l}\text { Nome dos } \\
\text { perfumes }\end{array}$ & $\begin{array}{l}\text { Código usado } \\
\text { na pesquisa }\end{array}$ & Descrição da fragrância \\
\hline True Force & A & $\begin{array}{l}\text { O perfume traduz o sentimento de admiração, de } \\
\text { aventura, e do céu todo aberto representado por um } \\
\text { blend de ervas aromáticas, especiarias e madeiras bem } \\
\text { masculinas. }\end{array}$ \\
\hline $\begin{array}{l}\text { Ironman } \\
\text { Extreme }\end{array}$ & B & $\begin{array}{l}\text { Uma explosão de notas aquáticas com toques } \\
\text { amadeirados que transmite energia para superar todos } \\
\text { os limites. }\end{array}$ \\
\hline Spirit & D & $\begin{array}{l}\text { O prazer das coisas simples da vida. Traz a sofisticação } \\
\text { de uma fragrância clássica em perfeita harmonia com } \\
\text { notas modernas e atuais. Para o homem elegante, que } \\
\text { acompanha o seu tempo. }\end{array}$ \\
\hline Signature & $\begin{array}{l}\text { Uma fragrância marcante para homens que interpretam } \\
\text { o clássico a sua maneira. Traduz sofisticação e } \\
\text { modernidade, através da combinação de notas frutais } \\
\text { intensas e releituras de notas consagradas da perfumaria } \\
\text { masculina, como o musk e âmbar. }\end{array}$ \\
\hline $\begin{array}{l}\text { Christian } \\
\text { Lacroix Nuit }\end{array}$ & E & $\begin{array}{l}\text { Uma atraente fantasia de essências de folhas intensas } \\
\text { e lavanda, combinadas com a sedução de misteriosas } \\
\text { madeiras. }\end{array}$ \\
\hline
\end{tabular}

Tabela 2. Discurso verbal de cada um dos perfumes masculinos selecionados.

Fonte: Elaborado pelos autores com base na pesquisa (2014). 


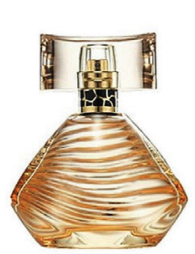

1

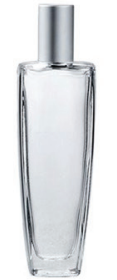

2

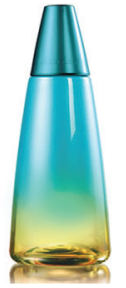

3

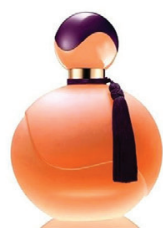

4

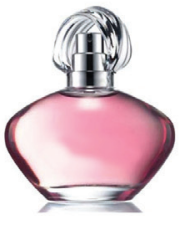

5

Figura 3. Perfumes femininos tal como apresentados no questionário

Fonte: Elaborado pelos autores com base na pesquisa (2014).

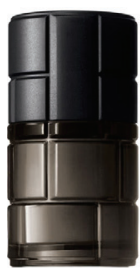

A

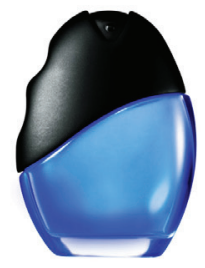

B

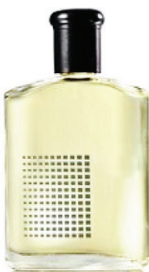

C

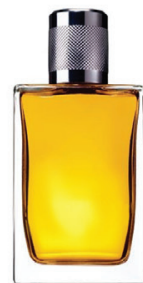

D

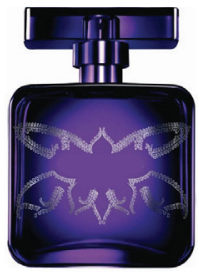

$\mathbf{E}$

Figura 4. Perfumes masculinos tal como apresentados no questionário Fonte: Elaborado pelos autores com base na pesquisa (2014).

\subsection{Análise dos resultados}

Quando questionados sobre a importância de uma embalagem, mais da metade dos participantes afirmam que ela é tão importante quanto o perfume. Quando se trata de um perfume para uso próprio, $40 \%$ afirmam que a embalagem não importa contanto que o perfume (cheiro) seja atraente. Enquanto que 56\% dizem que ela é tão importante quanto o cheiro. No entanto, quando se trata de uma compra para presente, os resultados são bem diferentes. Apenas $11 \%$ dizem que a embalagem não é tão importante. A maioria (84\%) diz que a embalagem deve ser tão atraente quanto o cheiro. Além disso, $6 \%$ afirmam que a embalagem deve ser atraente mesmo que o perfume não seja tão bom. Nesse sentido, podemos inferir que a embalagem desempenha um papel importante em termo de atratividade.

Porém, argumentamos que, mais do que atratividade, uma embalagem deve estar em consonância com as mensagens e promessas de uma fragrância . Deve fazer sentido para o consumidor, de forma que as características que fazem-no sentir-se atraído por uma embalagem estejam em consonância com o cheiro. Uma embalagem deve tanto elevar expectativas quanto estar 
em sintonia com elas. Nem sempre o consumidor terá a oportunidade de experimentar o perfume, em casos como vendas diretas (na ausência de amostras grátis) e vendas por websites. Diante disso, os discursos publicitários cumprem o papel de informar o consumidor os efeitos e características de cada um dos perfumes. Sabe-se porém que a comunicação visual também desempenha o mesmo papel de informar esse mesmo consumidor. Ainda que de forma indireta, por não fazer uso de palavras. Nesse caso, é importante que as mensagens e as imagens estejam em sintonia. Por mais óbvio que isso possa parecer, os resultados obtidos na pesquisa indicam que em algumas situações a sintonia entre discurso publicitário e design de embalagem precisa ser aprimorada.

A primeira frase apresentada "Fragrância delicada, com direção olfativa floral amadeirada, indicada para o dia. Mantém-se serena no caos, pois nada nem ninguém interfere em seu equilíbrio" representa o perfume Pure Blanc (embalagem número 2). A embalagem transparente com tampa na cor prata aparentemente estaria de acordo com os atributos de delicadeza, serenidade e equilíbrio que se deseja passar. Porém, a embalagem correspondente foi a menos votada. A opção mais votada (30\%) foi a de número 5, seguida a numero 1 (22\%), número 4 (19\%), número $3(17 \%)$ e finalmente a opção de número 2 $(12 \%)$. Ao analisar as duas opções mais votadas podemos inferir que a descrição floral amadeirada possivelmente leva o consumidor a associar a fragrância com a cor rosa (por ser uma cor comum às flores) e tons de marrom (por causa da madeira).

"Fragrância delicada, com direção olfativa floral amadeirada, indicada para o dia. Mantém-se serena no caos, pois nada nem ninguém interfere em seu equilíbrio."

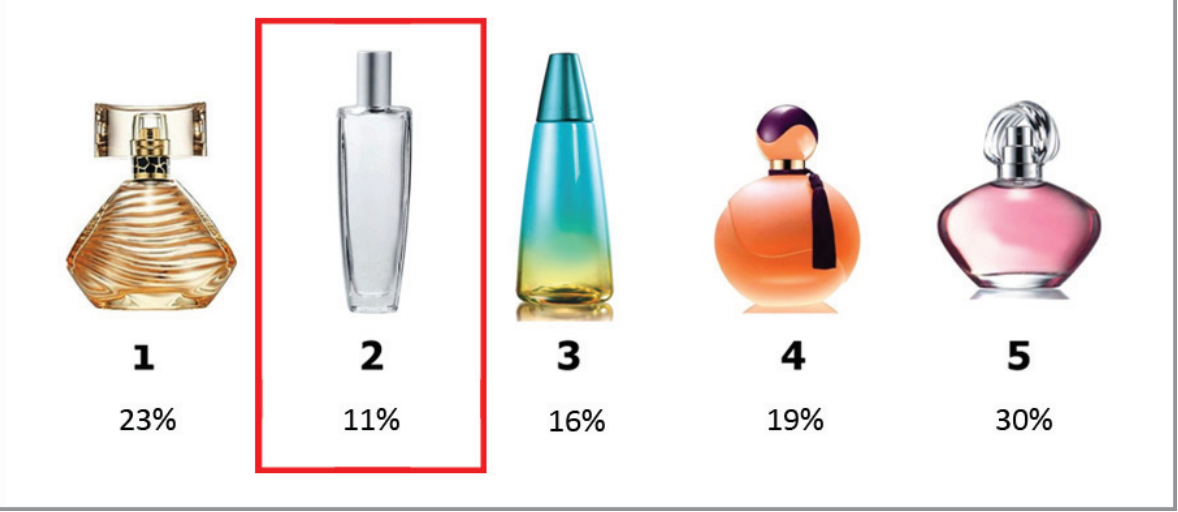

Figura 5. Respostas para primeira frase de perfumes femininos. Fonte: Elaborado pelos autores com base na pesquisa (2014). 
A segunda frase apresentada "Liberte seus desejos mais selvagens com esta fragrância que combina a refrescância de folhas verdes, exóticas camélias e a sensualidade do sândalo" representa o perfume Instinc (embalagem número 1). A embalagem desse perfume possui um forma que sugere o exótico e o selvagem. As listras (possivelmente da textura do frasco) lembram a pele de um animal selvagem como o tigre. E, por fim, a cor amarronzada se relaciona com o ativo do sândalo. No entanto, a opção correta não foi a mais votada. Apenas $19 \%$ indicaram a embalagem número 1 . A opção mais votada foi a de número 3 , uma embalagem com cores azul, verde e amarelo. Acreditamos que nesse caso o texto "refrescância de folhas verdes" tenha influenciado nas respostas. é possível que ao se deparar com a palavra verde os entrevistados tenham associado à embalagem que continha tal cor.

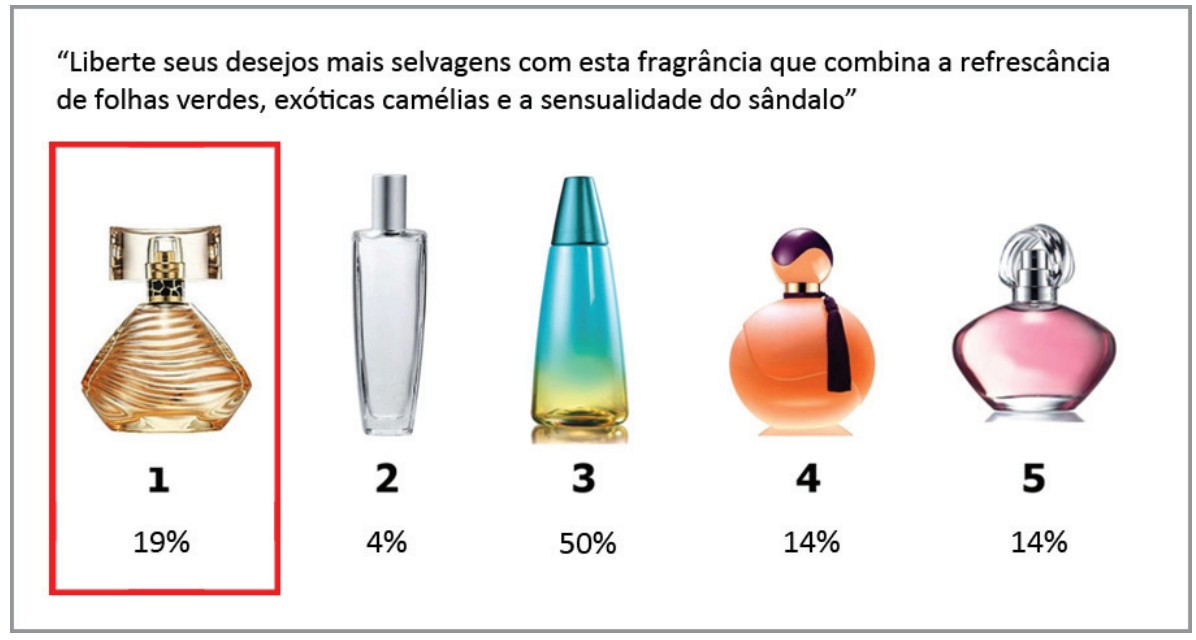

Figura 6. espostas para segunda frase de perfumes femininos.

Fonte: Elaborado pelos autores com base na pesquisa (2014).

A terceira e última frase para representar um perfume feminino foi a única na qual a resposta mais votada (40\%) correspondia a embalagem correta. A frase "Uma viagem inspiradora interpretada por um mix de especiarias do Oriente e rosa de açafrão, com a sensualidade do musk e âmbar" representa a embalagem de número 4, do perfume Far Away Exotic. As cores laranja (uma cor quente representando o mix de especiarias) e roxo (uma cor que pode ser associada a sensualidade) somadas ao pingente pendurado no frasco decerto tornam a embalagem como a melhor opção. Apesar disso duas outras opções receberam uma considerável quantia de votos. A embalagem de numero 1 obteve $30 \%$ dos votos e a embalagem 5, 20\%. A número um é aquela de tons amarronzados que por também ser um tom quente poderia ser relacionado ao discurso. É uma embalagem que também transmite sensualidade. Já a embalagem de número 5 , pela cor rosa pode ter sugerido a dita sensualidade. 
"Uma viagem inspiradora interpretada por um mix de especiarias do Oriente e rosa de açafrão, com a sensualidade do musk e âmbar."

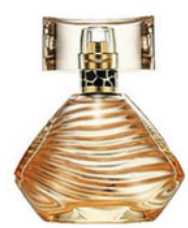

1

$30 \%$

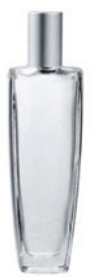

2

$1 \%$

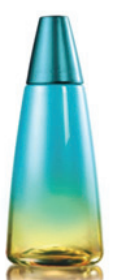

3

$9 \%$
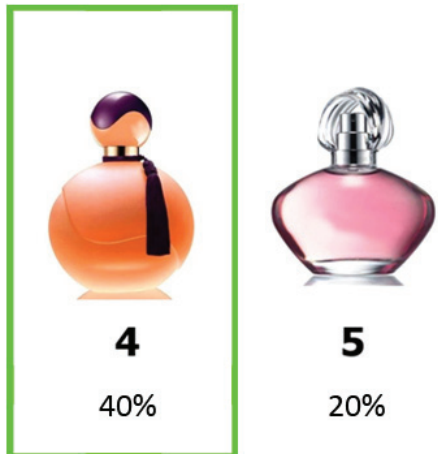

5

$20 \%$

Figura 7. Respostas para terceira frase de perfumes femininos.

Fonte: Elaborado pelos autores com base na pesquisa (2014).

Da quarta frase em diante as opções estavam relacionadas a perfumes masculinos. A quarta frase, "Uma explosão de notas aquáticas com toques amadeirados que transmite energia para superar todos os limites", representa o perfume Ironman Extreme. Esta foi a embalagem com maior porcentagem de acertos (63\%). Podemos inferir que as palavras "notas aquáticas" influenciaram na escolha da embalagem de cor azul. A combinação com o preto faria jus ao termo explosão. Como segunda opção mais votada temos a embalagem de número 1(15\%). É possível que as cores preta e cinza em um formato de embalagem que lembra uma granada pode ter sugerido a tal explosão de notas aquáticas.

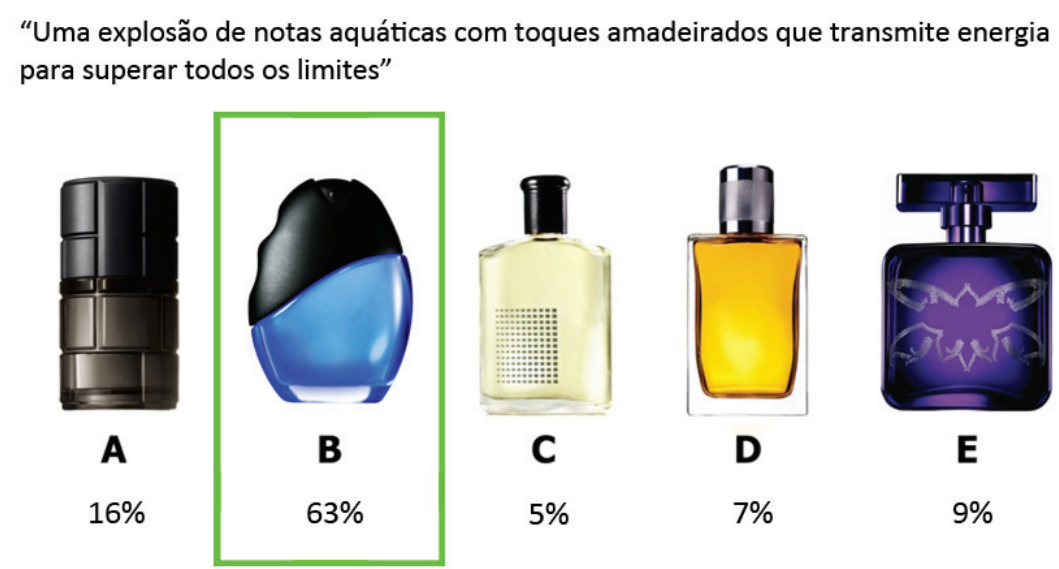

Figura 8. Respostas para primeira frase de perfumes masculinos.

Fonte: Elaborado pelos autores com base na pesquisa (2014). 
A quinta frase, "O prazer das coisas simples da vida. Traz a sofisticação de uma fragrância clássica em perfeita harmonia com notas modernas e atuais. Para o homem elegante, que acompanha o seu tempo", representa o perfume Spirit (embalagem B). Nesse caso, a opção correta também obteve a maioria dos votos (47\%). A segunda opção mais votada foi a de letra D com $22 \%$, seguida pela embalagem de letra A (17\%). A embalagem de Spirit com o líquido de cor clara faz com que esta seja uma boa associação às "coisas simples da vida". Sua embalagem de formato mais tradicional se associa ao atributo "fragrância clássica”. É interessante notar que a segunda mais votada é aquela que mais se aproxima da embalagem de Spirit. Já a terceira opção apontada como correta pode ser devido a uma alusão ao moderno.

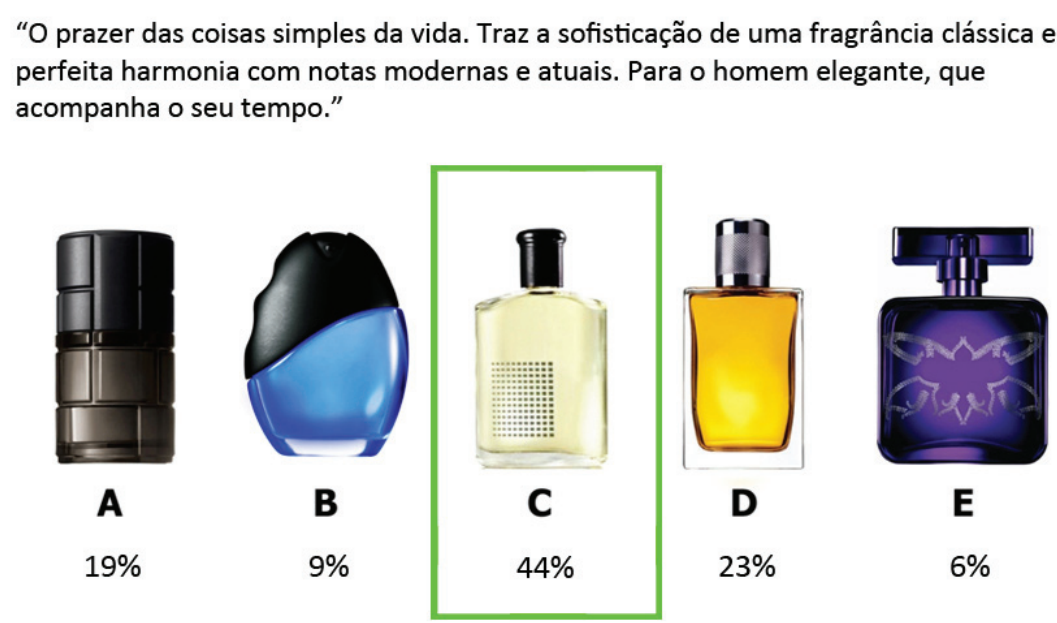

Figura 9. Respostas para segunda frase de perfumes masculinos.

Fonte: Elaborado pelos autores com base na pesquisa (2014).

Finalmente, a sexta frase, "Uma atraente fantasia de essências de folhas intensas e lavanda, combinadas com a sedução de misteriosas madeiras" corresponde ao perfume Christian Lacroix Nuit. A embalagem correspondente (letra E) foi a mais escolhida (39\%). Porém a segunda mais votada, embalagem de letra D também obteve considerável número de votos (32\%), deixando bem próxima da primeira. Acreditamos que o nome dos ingredientes foram decisivos na escolha dessas opções. A "Lavanda" levou a associação à cor roxo (pela cor da flor em si) enquanto que as "madeiras" levaram a associação à cor marrom amarelado. 
"Uma atraente fantasia de essências de folhas intensas e lavanda, combinadas com a sedução de misteriosas madeiras"

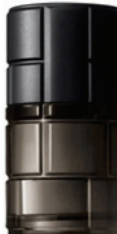

A

$13 \%$

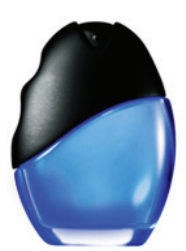

B

$3 \%$

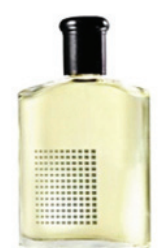

C

$15 \%$

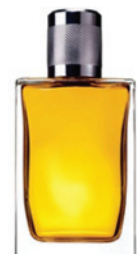

D

$30 \%$

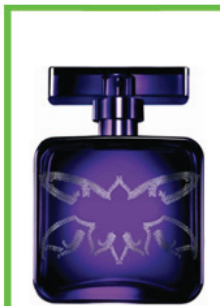

E

$39 \%$

Figura 10. Respostas para terceira frase de perfumes masculinos.

Fonte: Elaborado pelos autores com base na pesquisa (2014).

Das respostas obtidas nessa pesquisa concluímos que determinadas palavras levam a associação de determinadas cores. Essas palavras podem ser mais ou menos subjetivas. Quando se trata de palavras que levam a associação àquilo que é concreto (substantivos como lavanda e madeira) as respostas são mais precisas. Quando se tratam de palavras que transmitem sensações e qualidade as respostas podem variar mais por se tratar de algo mais pessoal.

\section{Considerações finais}

Pesquisas têm demonstrado o crescimento do mercado de perfumes e produtos fragrantes no país. De acordo com a Associação Brasileira de Industria de Higiene Pessoal Perfumaria e Cosméticos, o mercado de fragrância em 2012 foi de R $\$ 12.66$ bilhões, em 2013 teve o valor estimado de $\mathrm{R} \$ 14.2$ bilhões, sendo as projeções para os próximos anos de contínuo crescimento ${ }^{4}$. Além disso, os meios digitais se configuram como uma nova plataforma de mercado para o comércio de tais produtos. Empresas de cosméticos estão investindo em lojas e catálogos virtuais ${ }^{5}$. Apesar de sabermos que a decisão de compras de produtos fragrantes prescinde um contato físico com o produto. Logo, torna-se relevante estudar de qual forma a experiência na internet poderá ser mais próxima daquela vivenciada no ponto de venda físico. Apesar das

4. Caderno de Tendências 2014-2015. Disponível em < http://www.abihpec.org.br/2013/10/caderno-de-tendencias-2014-2015/> Acesso em 15/08/2014.

5. O dilema do e-commerce para Natura, Avon e O Boticário. Disponível em http://epocanegocios. globo.com/inspiracao/ empresa/noticia/2013/08/o-dilema-do-e-commerce-para-natura-avon-e-o-boticario.html. Acesso em 22/07/2014 
especulações a cerca do uso de estímulos olfativos em plataformas digitais ${ }^{67}$, hoje não existe tal possibilidade no comércio eletrônico. Portanto, na ausência de estímulos olfativos, estímulos audiovisuais se apresentam como uma alternativa para comunicação .

O presente artigo vem de encontro com essas tendências de consumo e as novas plataformas de mercado. Acreditamos que uma pesquisa em linguagens visuais irá auxiliar na comunicação dos atributos de uma fragrância em situações nas quais a experiência de se testar um perfume não for possível. Da amostra de perfumes selecionada nessa pesquisa, dois terços apresentaram um resultado positivo. Isto é, os participantes identificaram uma sincronia entre mensagem e embalagem. No entanto, as demais embalagens não foram identificadas em consonância com o discurso publicitário. Assumimos que essa pesquisa demanda uma investigação mais aprofundada. Sendo importante analisar os demais produtos dessa e de outras empresas. A identidade de um perfume não é apenas seu cheiro, suas mensagens publicitárias e sua embalagem. Mas um conjunto integrado dessas facetas e como tal combinação percepção do consumidor. Logo, quanto mais os designers investigarem e compreenderem a percepção dos consumidores, mais eficiente serão os resultados de seus projetos.

\section{Referências}

DEMATTÈ, M. L.; SANABRIA, D.; SPENCE, C. Cross-Modal Associations Between Odors and Colors. Chemical Senses, v. 31, p. 531-538, 2006.

DONNA, L. Fragrance Perception: Is Everything Relative? Perfumer \& Flavorist, v. 34, p. 26-35, 2009. Disponível em http://www.fragrancesoftheworld.com/downloads/Fragrance\%20Perception\%20-\%20Is\%20 Everything\%20Relative.pdf. Acesso em 10/01/2014.

GILBERT, A. N.; MARTIN, R.; KEMP, S. E. Cross-Modal Correspondence between Vision and Olfaction: The Color of Smells. American Journal of Psychology, vol. 109, n. 3, p. 335-351, 1996.

\footnotetext{
6. Computers will taste, smell and hear within five years, IBM predicts. Disponivel em http://www. washingtonpost.com/business/technology/computers-will-taste-smell-and-hear-within-five-years-ibm-predicts/2012/12/17/7b8c0c44-4858-11e2-ad54-580638ede391_story.html. Acesso em 20/08/2014.

7. Google nose. Disponível em https://www.google.com/landing/nose/. Acesso em 20/08/2014 
KIM, Y. Can eyes smell? Cross-modal correspondences between color huetone and fragrance family. Color Research \& Application, v. 38, ed.2, p. 139-156, 2013.

MALNIC, B. O cheiro das coisas - o sentido do olfato: paladar, emoções e comportamentos. Rio de Janeiro: Vieira \& Lent, 2008.

MORROT, G., BROCHET, F., DUBOURDIEU, D. (2001). The Color of Odors. Brain and Language, v. 79, p. 309-320, 2001.

SILVA, C. A. P. Perfume, história e design: o papel das embalagens no mercado brasileiro de perfumaria. 2012. Dissertação (Mestrado em Design) - Universidade do Estado do Rio de Janeiro, Escola Superior de Desenho Industrial, Rio de Janeiro.

SILVA, C. A. P.; CAMPOS, J. L. de; LIMA, G. S. da C. O design de embalagens para perfumes em um cenário pós-moderno. BOCC. Biblioteca On-line de Ciências da Comunicação, v. 12, p. 1-10, 2011. Disponível em: <http://www. bocc.ubi.pt/_esp/anopub.php? anopub=2011>. Acesso em 11/01/2014.

TEIXEIRA, M. A. et al. Perfume Engineering: Design, Performance \&Classification. Oxford, UK: Elsevier, 2013.

WOLFE, J. M. et al. Sensation \& Perception(3rd Edition). Sunderland, MA: Sinauer Associates.

ZARZO, M.; STANTON, D.T. Understanding the underlying dimensions in perfumers' odor perception space as a basis for developing meaningful odor maps. Attention, Perception \& Psychophysics, n. 71, p.225-247, 2009. 
Recebido em: 30/04/2014

Aceito em: 01/06/2014

\section{Como citar}

SILVA, Camila Assis Peres; MAZZILLI, Clice Sanjar. A identidade de um perfume: análise da relação entre design de embalagem e mensagem publicitária. Arcos Design. Rio de Janeiro: PPD ESDI UERJ. Volume 8 Número 1 Junho 2014. pp. 62-77. Disponível em: [http://www.e-publicacoes.uerj.br/index.php/arcosdesign]

\section{DOI}

http://dx.doi.org/10.12957/arcosdesign.2014.13926

\section{(c) (1) (3)}

A Revista Arcos Design está licenciada sob uma licença Creative Commons Atribuição - Não Comercial - Compartilha Igual 3.0 Não Adaptada. 